\title{
CRISE MIGRATÓRIA NA ALEMANHA: DISCURSOS QUE ABREM E FECHAM FRONTEIRAS

\author{
VICTOR CARREÃO 1
}

\author{
Programa de Pós-Graduação em Linguística \\ Instituto de Estudos da Linguagem - Universidade Estadual de Campinas \\ vcarreao@yahoo.com.br
}

\begin{abstract}
Resumo. A Alemanha tornou-se um dos países que mais acolheu refugiados dos conflitos armados na região da Síria. A chanceler Angela Merkel, com sua política de fronteiras abertas, vem sendo criticada, principalmente pelo partido Alternative For Germany (AFD) - representado por Frauke Petry -, que fez fortes ressalvas a esta prática e alegou que imigrantes ilegais deveriam ser impedidos, com o uso da força, caso necessário. O corpus de análise deste trabalho é composto por uma declaração de Merkel ao povo alemão e de uma entrevista concedida por Petry. Tendo como principal referencial teórico-metodológico a sequência de trabalho sobre corpus discursivo, apresentada por Courtine (2009), verificou-se a motivação dos atos de fala de ambas as locutoras no cruzamento entre legislação e política. Palavras-chave: crise dos refugiados; corpus discursivo; sequência discursiva; interdiscurso.
\end{abstract}

\begin{abstract}
Germany has become one of the countries that most hosted refugees from armed conflicts in the region of Syria. Chancellor Angela Merkel, with her policy of open borders, has been criticized, especially by the party Alternative For Germany (AFD) - represented by Frauke Petry, who made strong caveats to this practice and claimed that illegal immigrants should be stopped, with use of force if necessary. The analytical discursive corpus of this work consists of an announcement made by Merkel to the German people and an interview given by Petry. Its theoretical framework is based on the work sequence on discursive corpus proposed by Courtine (2009), which showed an overlap between law and politics in both speakers' motivation for speech acts.
\end{abstract}

Keywords: refugees' crisis; discursive corpus; discursive sequence; interdiscourse.

\section{Introdução}

A proposta deste trabalho é tratar de aspectos de formação discursiva temática: $a$ crise dos refugiados na Europa. Tal escolha está associada a uma grande variedade de textos e proferimentos que circulam em jornais e mídias sociais, cabendo ao pesquisador selecionar arquivos que possam apresentar a questão a ser debatida e analisada

\footnotetext{
${ }^{1}$ Mestrando em Linguística pelo Programa de Pós-Graduação em Linguística (IEL-Unicamp).
} 
(MAINGUENEAU, 2008b, p. 18). Neste artigo, esta seleção objetiva mostrar como o aumento no fluxo migratório para a Europa trouxe à tona questões que estão além do rótulo "ajuda humanitária". Por vezes, visto como o "centro colonizador", o continente europeu vem atraindo olhares, sejam de pena ou de interesse, não apenas de suas próprias nações, mas de países ao redor do globo para o que foi chamado de "a segunda maior crise de refugiados do mundo" ". Muitos são os afetados por esta crise e, a cada dia, mais e mais notícias contabilizam o crescente número de migrantes.

A divulgação da mídia, nos últimos meses, teve foco na abertura das fronteiras europeias aos refugiados. Uma das razões para esse fenômeno migratório é o conflito na Síria, que teve início em meados de $2011^{2}$ - logo após a Primavera Árabe -, e o grande fluxo de refugiados em direção à Europa, que enfrenta dificuldades para conseguir abrigo em solo europeu; portanto é comum associar os dois acontecimentos.

Os milhares de refugiados sírios ${ }^{3}$, por muitas vezes, encontraram em suas rotas de fuga as grades e arames farpados dos europeus - quando não acompanhados por seus cordões policiais. Muitos governantes seguiram as diretrizes da Organização das Nações Unidas (ONU) de que as fronteiras dos europeus deveriam permanecer controladas, mas que os refugiados deveriam ser recebidos ${ }^{4}$. Um dos países que mais se destacou por esta abertura das fronteiras foi a Alemanha, cuja atual chanceler, e grande defensora da abertura das fronteiras, é Angela Merkel - membro do partido União Democrata-Cristã (CDU).

Por sua posição a favor dos refugiados, Merkel foi eleita a pessoa do ano pela revista Time, em 2015, e muito elogiada por diferentes líderes políticos ao redor do mundo ${ }^{5}$. Contudo, sua política de ajuda externa nem sempre foi vista como ideal, principalmente por muitos de seu próprio povo - resultando em momentos violentos de protestos contra os refugiados ${ }^{6}$. Sua contraparte é o partido de extrema direita "Alternative for Germany" (AFD), que vem ganhando espaço político por conta da crise imigratória, representado por Frauke Petry. Este ponto de conflito ilustra bem a crise dos imigrantes.

Como corpus a ser estudado, analisou-se um pronunciamento de fim de ano de Merkel $^{7}$ proferido ao término de 2015 (MERKEL, 2016) e dirigido ao povo alemão, em que é feito um balanço da imigração, as oportunidades que tal fenômeno traz, e que contém considerações sobre o espírito da nação alemã. Analisou-se, também, uma entrevista concedida por Petry a um canal alemão (DW) (PETRY, 2016), em que a discussão gira em torno de uma declaração polêmica de Petry sobre abrir fogo, se necessário, contra imigrantes que tentassem cruzar as fronteiras alemãs de maneira ilegal ${ }^{8}$.

Tomando como principal referencial teórico-metodológico a sequência de trabalho sobre um corpus discursivo, proposta por Courtine (2009), o objetivo deste artigo foi analisar as duas falas de Merkel e de Petry, comentadas acima, a fim de verificar qual seria a constituição de seus dizeres; o porquê de dizer o que dizem. A hipótese inicial foi de que este embate, ser ou não ser uma nação aberta à migração, vai além de questões humanitárias, tendo suas raízes, possivelmente, em questões sociopolíticas do governo 
alemão. Todos os trechos aqui mencionados são traduções nossas dos documentos oficiais, ou transcrições de discursos, em inglês ${ }^{2}$.

\section{O corpus discursivo e suas etapas de pesquisa}

Courtine (2009, p. 111-114) define o corpus discursivo como o "conjunto de sequências discursivas, estruturado segundo a articulação, o cruzamento, ou a composição de dois planos de determinação". Os planos de determinação relacionam um sujeito de enunciação e uma situação de enunciação, ambos permeados por três domínios: da memória, "sequências discursivas que preexistem à sequência discursiva de referência"; da atualidade, "conjunto de sequências discursivas que coexistem com a sequência discursiva de referência em uma conjuntura histórica determinada"; e da antecipação, "relações interpretáveis como efeitos de antecipação".

Para Courtine (2009, p. 116), a primeira etapa de um trabalho sobre corpus é determinar as "formulações de referência" no intradiscurso - a organização sintagmática realizada por um sujeito - de uma sequência discursiva de referência, determinando e justificando a segmentação desta sequência. Após, a segunda etapa seria a filtragem destas formulações de referência. Ainda para Courtine (2009, p. 100), tal fator deveria ser pensado como "um processo de reconfiguração incessante no qual o saber de uma FD [Formação Discursiva] é levado, em razão das posições ideológicas que esta FD representa em uma conjuntura determinada, a incorporar elementos pré-construídos produzidos no exterior de si mesmo". Possenti (2009, p. 156) ressalta que "só estão disponíveis, para cada FD, os pré-construídos cujo sentido é evidente para essa FD”. O discurso é, assim, influenciado pela história.

Courtine (2009, p. 99) aponta que o domínio do saber de uma Formação Discursiva funciona como um "princípio de aceitabilidade discursiva para um conjunto de formulações (determina o que pode e deve ser dito), assim como um princípio de exclusão (determina o que não pode/deve ser dito)". Isso implicaria dizer que um discurso possui textos a que recorre a fim de legitimar o que é dito. Estes textos estariam presentes nos "núcleos de invariância" de um discurso, auxiliando na revelação da identidade por trás do que é dito. Utilizar-se de uma formação discursiva, ou mais de uma, é construir uma identidade ( $c f$. MAINGUENEAU, 2015, p. 82).

Os enunciados são definidos, segundo Courtine (2009, p. 100), como "os elementos do saber próprio a uma FD. Conceberemos o enunciado como uma forma ou um esquema geral que governa a repetibilidade no seio de uma rede de formulações". Para verificar esta "repetibilidade", chega-se, então, à terceira etapa da análise de corpus, de acordo com Courtine (2009, p. 118), em que subcorpora deverão ser analisados. Os domínios de memória, atualidade e antecipação são, aqui, evocados a fim de identificar a interdiscursividade presente.

Maingueneau (2015, p. 155) diz que a memorabilidade de um discurso está relacionada ao fato de saber o que guardar de determinado acontecimento - especialmente

${ }^{2}$ Notas com referência às notícias jornalísticas, que dão suporte à análise, podem ser encontradas ao término deste trabalho. 
pelo fato de diferentes tipos de armazenamentos de dados permitirem a gravação de todo e qualquer discurso, por exemplo. Saber o que selecionar e trazer à tona em um discurso seria auxiliar na hierarquização entre os gêneros do discurso. É neste processo escalonado de diferentes discursos que Achard (1999, p. 14) mostra que a escolha do que será resgatado é importante, pois "o passado, mesmo que realmente memorizado, só pode trabalhar mediante as reformulações que permitem reenquadrá-lo no discurso concreto face ao qual nos encontramos".

A quarta etapa da análise de corpus refere-se à constituição do enunciado. Courtine (2009, p. 119) mostra que "a intuição de uma repetibilidade" que preside o reagrupamento das formulações [frases e trechos] na propriedade de se "fazer enunciado" permite ascender a esquemas gerais que ordenam o processo discursivo. Logo, poder-seia mostrar o que determinado sujeito, em determinada situação, pode e não pode dizer pela repetição de um mesmo argumento. Embora responsável por seu enunciado, para Maingueneau (2014, p. 40-43), o sujeito é sempre impulsionado ao dizer de sua classe de locutores. Assim, o sujeito é o meio pelo qual o enunciado se materializa, trazendo influências de formações discursivas a que foi exposto.

Um retorno ao intradiscurso (à fala dos sujeitos) é necessário para que se possa, por fim, verificar os "pontos nodais", como definidos por Courtine (2009, p. 120), que mostram como a sequencialização discursiva realiza-se. Para tanto, a seguir, será exposta a análise das falas propostas.

\section{A ordem do discurso}

Entender o que acontece no continente europeu é o ponto de partida, antes de tudo, para esta análise. A guerra civil na Síria, o receio crescente em torno do terrorismo como os atentados terroristas de Paris (em 13 de novembro de 2015) e na Bélgica (em 22 de março de 2016) -, junto a fatores como a recente crise econômica, com perda de empregos formais na Grécia, oferecem um panorama da condição de produção dos discursos sobre migração.

\section{a. Condições de produção}

Variáveis pertinentes ao enunciador, para Courtine (2009, p. 46-47), dão base às condições de produção de um discurso. A condição social dos interlocutores e o contexto social da comunicação, por exemplo, somam-se aos objetivos e gêneros de um texto a ser enunciado. Considerar o gênero do texto é considerar seu campo de atividade (MAINGUENEAU, 2015, p. 67) e isso faz com que um mesmo discurso possa ser analisado diferentemente conforme a instituição social em que se encontrar. Para cada caso, determinado posicionamento pode ser observado confrontando outros. Alguns discursos de Merkel à comunidade internacional ${ }^{3}$ ajudam a delimitar as condições de

3 Transcrições

disponíveis

em

<https://www.bundesregierung.de/SiteGlobals/Forms/Webs/Breg/Suche/EN/Redensuche formular.html>

; acesso em abr. 2016. 
produção em que discursos sobre migração se sustentam, uma vez que várias variáveis socioeconômicas estão envolvidas nesta crise:

- 12/05/14 - Câmara do Comércio, em Washington: Crise na Ucrânia, Espionagem da Agência de Segurança dos EUA e redução de tarifas comerciais;

- 24/06/14 - Discurso à recepção de Corpos Diplomáticos, em Berlim: Mercado interno europeu e papel da OTAN na segurança;

- 08/02/15 - 51 a Conferência de Segurança de Munique, em Munique: Crise na Ucrânia, Livre comércio com os EUA e Terrorismo e Segurança;

- 11/03/15 - Discurso durante evento do jornal Asahi Shimbun, em Tóquio: Diálogo entre Japão e Alemanha e Iniciativas para geração de energia segura;

- 16/07/16 - Discurso à recepção de Corpos Diplomáticos, em Berlim: Mudanças climáticas e Crise Econômica Europeia;

- 28/09/15 - Discurso à Iniciativa das Nações Unidades pelo Desenvolvimento Sustentável, em Nova York: Luta contra a pobreza no mundo e Estratégias Nacionais de Sustentabilidade;

- 14/10/15 - Discurso ao Parlamento Europeu, em Strasbourg: Crise dos Refugiados - menção à resolução do Parlamento Europeu (datada de 10/09/15) e aos procedimentos da Convenção de Dublin (que regulamenta o deslocamento de refugiados dentro da Europa);

- 04/02/16 - Conferência de Suporte à Síria e Região, em Londres: Guerra Civil na Síria e Crise dos Refugiados.

Algumas palavras-chave puderam ser apontadas durante a análise das transcrições das elocuções acima, quais sejam:

- Segunda Guerra Mundial;

- Refugiados;

- Imigração;

- Fronteiras;

- Leis (também referido como "regulamentações" ou "estado de direito").

Estas palavras apareceram relacionadas à crise migratória nas falas acima e são o ponto de partida para essa análise. Em termos legislativos, a Alemanha - em seu artigo 16 da Lei Básica - discorre sobre a concessão de asilo político e ajuda a refugiados. Há também o artigo 17 da Convenção de Dublin - destinado aos membros da União Europeia e contendo diretrizes sobre casos de asilo político, fluxo de refugiados e versando sobre responsabilidades humanitárias.

Pode-se observar que estes artigos são mencionados em alguns dos discursos destacados acima, mas não dizem respeito, necessariamente, aos interlocutores do discurso - aqueles que o ouvem. Assim, regulamentações alemãs são utilizadas junto com as europeias para dar força à argumentação em certos momentos. 


\section{b. Formações discursivas}

Nas falas de Merkel a autoridades internacionais, regulamentações são mencionadas, mas não em demasiado. E ao povo alemão? Os estatutos que servem de base aos partidos políticos de Merkel e de Petry e ditam as condições discursivas do que "pode ou não pode ser dito" são alguns exemplos que regem a gênese de seus respectivos discursos. O CDU de Merkel possui, em seu fundamento, o seguinte trecho:

Tendo em vista os desafios do século 21, é necessário encontrar uma nova definição para a segurança. Ela engloba a segurança interna e externa do mundo, com suas crescentes novas ameaças. Além disso, inclui segurança social nas condições de uma economia globalizada e as mudanças demográficas, bem como os referentes à coesão da nossa sociedade e a garantia também para viver em um ambiente em que valha a pena viver e que cada geração preserve a próxima geração. (CDU, 2008, p. 05; grifos nossos)

Já para o AFD de Petry:

Após a Segunda Guerra Mundial, a República Federal da Alemanha experimentou uma fase extremamente bem-sucedida de desenvolvimento político, económico e social. O motivo foi a interação harmoniosa, implícita pela Lei Básica, da democracia, do Estado de Direito, a separação dos poderes, da subsidiariedade, e uma economia social de mercado.

O novo partido político Alternative für Deutschland foi fundado como uma reação de muitos cidadãos interessados e responsáveis de espírito para o fracasso da liderança política na crise do euro e em lidar com problemas políticos. Isto é particularmente verdade para as políticas de energia, mercado de trabalho, da família e de imigração.

(AFD, 2016b, p. 01; grifos nossos)

As relações entre os países do bloco europeu tornaram o continente integrado, seja em aspectos de transporte ou pelo uso de uma moeda única. Fez-se necessário, então, pensar a governabilidade da nação sempre em consonância com seus vizinhos. Há menção a estas relações nos trechos destacados acima. O AFD faz uma ressalva a esta relação internacional que a Alemanha exerce, deixando claro que viu, nos governos passados, o "fracasso" em balancear a pressão externa que a nação recebia. A imigração é um dos tópicos mencionados que fariam parte deste acervo de "fracassos". Para dar força a este argumento, espera-se que o AFD, principalmente por ser um partido oficialmente recente na política alemã, tenha em seu manifesto propostas de mudanças. Esse é um ponto de partida em que estes textos passam a trilhar caminhos diferentes - ainda que paralelos no campo das leis alemãs. Em relação à imigração, destacamos nas diretrizes dos partidos: 
Quadro 01. Diretrizes dos partidos em relação à migração.

\begin{tabular}{|c|c|}
\hline $\mathrm{CDU}$ & AFD \\
\hline \multirow{2}{*}{$\begin{array}{l}\text { Art. 127. Comprometimento com a liberdade } \\
\text { da arte, o que inclui apoiar os trabalhos de } \\
\text { refugiados e imigrantes; }\end{array}$} & $\begin{array}{l}\text { Art. 1. O foco do AFD é garantir os direitos } \\
\text { básicos enumerados pela Lei Básica; }\end{array}$ \\
\hline & \multirow{3}{*}{$\begin{array}{l}\text { Art. 2. Diversos dispositivos da lei precisam } \\
\text { de reformas urgentes, pois encontram-se } \\
\text { incompreensivos ou obsoletos. Entre eles, por } \\
\text { exemplo, regulamentação de impostos, } \\
\text { pensão, leis trabalhistas, seguros médicos e } \\
\text { leis de imigração; }\end{array}$} \\
\hline $\begin{array}{l}\text { Art. 129. Comprometimento em não negar e } \\
\text { se esquecer de todos aqueles deslocados } \\
\text { graças às ações alemãs durante a Segunda } \\
\text { Guerra Mundial; }\end{array}$ & \\
\hline \multirow{2}{*}{$\begin{array}{l}\text { Art. 306. Com base no conceito Cristão de } \\
\text { humanidade, por razões humanitárias, o país } \\
\text { deverá aceitar pessoas sob o título de } \\
\text { refugiados por razões humanitárias; }\end{array}$} & \\
\hline & $\begin{array}{l}\text { Art. 6. O AFD possui a opinião de que as } \\
\text { Forças Armadas da Alemanha deverão ser } \\
\text { utilizadas conforme o espírito da Lei Básica; }\end{array}$ \\
\hline $\begin{array}{l}\text { Art. 337. Integração através das fronteiras do } \\
\text { país, o que inclui o desenvolvimento gradual } \\
\text { de uma política de imigração, combate à sua } \\
\text { ilegalidade, combate a crimes e terrorismo. }\end{array}$ & $\begin{array}{l}\text { Art. 15. A política de imigração deve ser } \\
\text { legalmente estruturada com base em critérios } \\
\text { claros. Conhecimento da língua, educação, } \\
\text { habilidades vocacionais e os pré-requisitos do } \\
\text { mercado de trabalho alemão são fatores } \\
\text { decisivos para isso. Há a forte rejeição por } \\
\text { parte do partido em relaçãao à imigração dentro } \\
\text { dos sistemas sociais alemães [políticas } \\
\text { sociais]. Pedidos de asilo político serão } \\
\text { analisados de acordo com a Lei Básica. Por } \\
\text { razões humanitárias, temos a obrigação de } \\
\text { ajudar refugiados de guerra, seja aqui ou em } \\
\text { outras localidades seguras, com habitação e } \\
\text { suas necessidades. }\end{array}$ \\
\hline
\end{tabular}

Fonte: adaptado de CDU (2008) e AFD (2016b) (grifos nossos).

O CDU aparenta, nos trechos acima, manter viva a memória da Segunda Guerra Mundial e dela utiliza-se para propor artigos concernentes àqueles deslocados e impedidos de retornar a suas casas. O AFD faz menção à Segunda Guerra Mundial, mas não a utiliza como argumento, uma causa implicando em uma reação, nos artigos de seu manifesto. Seu apelo se faz pela Lei Básica, sendo ela mecanismo a ser defendido e a que se deve recorrer em casos mais extremos - como o uso das forças armadas. Tal fato pode, inclusive, fazer uma menção não explícita à Segunda Guerra, uma vez que as forças armadas não seriam utilizadas única e exclusivamente para a defesa do território nacional. O destaque principal vem no trecho destacado do artigo 15 da AFD: propiciar ajuda "aqui ou em outras localidades". Mais considerações acerca da imigração são levantadas no Manifesto de 2014 da AFD - Coragem para se levantar pela Alemanha: pela diversidade Europeia (AFD, 2016a, p. 02-03; grifos nossos):

- IV. 4: Imigração a fim de receber livre acesso aos serviços sociais alemães deve ser impedida. O fíctício uso de empregados autônomos deve ser combatido. As fronteiras externas da União Europeia devem ser monitoradas a fim de evitar imigração descontrolada dentro dos países da União Europeia. Ajuda humanitária a refugiados de guerra deve ser fornecida o mais perto possivel de suas casas;

- IV. 8: Políticas de harmonização devem ser limitadas em relação a riscos de saúde no cruzamento de fronteiras; 
- IV. 11: Como as utilidades públicas deverão ser disponibilizadas a seus consumidores deve ser uma decisão local, e não uma decisão da União Europeia.

Mais uma vez, neste segundo documento da AFD, observa-se que há a reiteração de que a ajuda humanitária deve ser realizada "o mais perto possível de suas casas". A questão de ajuda a refugiados, bem como sobre asilo político, aparenta se tornar mais radical de um documento para o outro e é claramente observada na fala analisada de Petry:

- E nós, nós nunca, você vê a AFD foi criada em 2013 e fomos nós que naquela época, em 2013 afirmamos que, por exemplo, em termos de política de migração, nós precisávamos, legalmente, de uma forma de distinguir entre leis de asilo e leis de migração, quando ... (PETRY, 2016; grifos nossos)

O manifesto do CDU aponta para diretrizes mais flexíveis, pautado por ideais humanitários, ao passo que o AFD segue a linha da Lei Básica como base para toda e qualquer diretriz que dita o curso do partido. Enquanto o CDU advoga por uma "economia globalizada", que é reforçada em seu manifesto por ações como a "integração através das fronteiras", o AFD busca resolver "o fracasso da liderança política" combatendo, entre outros problemas, a questão da imigração. A classificação da gestão CDU é enquadrada, conforme a posição do AFD, como um fracasso governamental. Assim, a posição esperada é que um partido de oposição, como o AFD, foque suas principais críticas nas fronteiras do país. Outro exemplo seria a proposta do AFD de que utilidades públicas deveriam ser geridas conforme "decisões locais". Mobilizar as forças armadas de acordo com as leis alemãs seria outro ponto atrelado à situação das fronteiras do país, sendo papel das forças de segurança proteger o país frente a ameaças.

Redefinir o conceito de asilo político e de imigração seria abrir caminho para que uma ou outra destas situações pudesse se enquadrar, por exemplo, sob a Lei de Obrigação dos Agentes Federais (comentada mais adiante) e o controle sobre a entrada e saída de pessoas na Alemanha pudesse ser mais rígido. O próprio manifesto do AFD (AFD, 2016a), "Coragem para se levantar pela Alemanha: pela diversidade Europeia", traz em seu título a questão da "diversidade europeia", que vai contra o princípio "globalizado" e "integralizado" do CDU. A crise dos refugiados seria um agravante em relação à discussão de uma Europa unificada e a legislação é o campo que permite que mudanças significativas sejam propostas com a garantia de sua execução.

\section{c. Interdiscurso}

Legislações servem de base aos manifestos dos partidos que, por sua vez, servem de base às falas das duas representantes políticas. Diferenças podem ser observadas, ainda que se comece a identificar uma base comum para o que é dito, por um critério de individuação que atribui a cada grupo "um certo número de particularidades de discurso" (COURTINE, 2009, p. 64). Como se pode observar em:

- Nossa língua, nossas regras e regulamentações. Todas essas coisas estão subjacentes a nossa sociedade e são requisitos fundamentais para a coexistência pacífica e de mútuo respeito de todas as pessoas de nosso país. Isso se aplica a todos aqueles que querem viver aqui. Imigração bem- 
sucedida beneficia um país tanto econômica como socialmente. (MERKEL, 2016; grifos nossos)

As "regulamentações" a que Merkel se refere são diretrizes apontadas pela Lei Básica Para a República Federal da Alemanha. Há alusão, em outros discursos proferidos pela Chanceler alemã, a outras leis referentes à União Europeia - dado o fato de que o grande fluxo imigratório afeta a todos os países europeus. A polêmica que cerca o discurso de Petry também possui raízes interdiscursivas:

- [Quando questionada sobre seu comentário de "atirar em imigrantes que ultrapassassem as fronteiras alemãs ilegalmente"] Sim, eu basicamente citei uma lei alemã que ainda existe. E como último recurso, o uso de armas é possível, mas estamos de acordo, estamos todos de acordo que nunca queremos isso, seria a última coisa a acontecer (PETRY, 2016; grifos nossos)

A lei citada por Petry diz respeito ao Artigo 11 (abrir fogo em serviços de fronteira), da "Lei sobre a obrigação direta do exercício da autoridade pública por agentes da lei da Federal". Valer-se de leis, bem como argumentar a favor de uma legislação que autoriza o uso de armas de fogo contra imigrantes ilegais, é uma maneira da AFD utilizarse de Aparelhos Ideológicos de Estado, descritos por Althusser (1985, p. 68) como "instituições distintas e especializadas". O uso das armas de fogo, propriamente dito, poderia ser considerado uma ação dos Aparelhos Repressores de Estado (ALTHUSSER, 1985, p. 69).

Ainda que com base no mesmo sistema legislativo, podemos identificar formações discursivas heterogêneas (MAINGUENEAU, 2015, p. 85). A legislação alemã pode ser um ponto comum para os dois discursos, porém há contradição dentro da própria lei em pontos sobre prestar ajuda - artigo 16 da Lei Básica - e reprimir a entrada ilegal - artigo 11 da lei de obrigação dos agentes federais. Os trechos analisados, até o momento, de Petry mostram-se mais claros que os de Merkel em relação à interdiscursividade: para a líder do AFD, a legislação alemã é um dos textos que lhe serve de base; para Merkel, a questão humanitária se mostra, em certos momentos, como este instrumento.

Contudo, há um exemplo - não neste corpus de análise - que merece destaque: um pronunciamento realizado por Merkel para seu partido político, o União DemocrataCristã (CDU), por conta de novas eleições em 2017. Nesta fala, após a promulgação da Resolução do Parlamento Europeu de 10 de Setembro/2015, Merkel adotou um tom mais flexível em relação à entrada de imigrantes propondo adaptar certos protocolos de entrada nas fronteiras alemãs, mas deixando claro que a Alemanha jamais deixaria de ajudar aqueles que necessitam de socorro, o que lhe rendeu palmas por mais de sete minutos ${ }^{9}$. Outra polêmica, desta vez ligada ao AFD, foi a prisão de Lutz Bachmann, líder do movimento anti-islã PEGIDA, que possuía muitos contatos com o partido de Petry ${ }^{10}$ relações estas que foram revistas pelo AFD após a prisão de Lutz. Esses acontecimentos ilustram o que para Maingueneau (2008a, p. 119) é visto como "a passagem de um discurso a outro [que] é acompanhado de uma mudança na estrutura e no funcionamento dos grupos que gerem esses discursos". 


\section{d. Memória}

A menção à Segunda Guerra Mundial é encontrada em documentos regulatórios relacionados à Alemanha e não é de se surpreender que ambos os partidos também a incluam em suas diretrizes políticas, tampouco que seja feita alusão a este evento muito bem marcado na história. Recorrer à memória deste conflito armado é, principalmente, comparar o fluxo de refugiados daquela época com os refugiados do conflito atual. Este é o exemplo mais claro de memória apresentado nos trechos analisados:

- O mundo possui atualmente mais refugiados do que qualquer período desde a Segunda Guerra Mundial. (MERKEL, 2016);

- [Quando questionada sobre lideranças racistas e xenófobas em seu partido] Desculpe-me, a AFD é feita de todos os tipos de cidadãos alemães e até mesmo pessoas que vivem no exterior, que pensam que a democracia falha frequentemente não só na Alemanha, mas também na Europa, que temos tratados que são dobrados, quando não quebrados, e que precisamos que os cidadãos se comportem novamente como cidadãos, e não apenas como consumidores. Então, é basicamente pessoas que partilham a ideia de preservar o que nós desenvolvemos após a Segunda Guerra Mundial. Não só na Alemanha, mas também na Europa. (PETRY, 2006)

Os trechos até aqui comentados ajudam a reforçar os conceitos da análise desta temática e mostram que, apesar de advir de um núcleo comum, a hierarquização das duas falas divide-se em um ponto: leis imigratórias. O percurso traçado inicia-se na memória de um conflito mundial que dará base à criação de uma legislação mais concernente às questões humanitárias. Inseridas em um contexto cada vez mais globalizado, estas leis procuram conciliar-se às normas maiores impostas pelo grande bloco econômico que é a União Europeia. Esta conexão regulamentadora, por si só, faz com que a identidade das nações seja colocada em questionamento. Por serem leis, sabe-se que estas devem ser obedecidas; por serem muitas e abrangentes, sabe-se que é possível selecionar e focar nas mais pertinentes a determinado plano de nação. Eis o ponto de divisão de ambos os lados aqui analisados.

A fala de Petry sobre os membros de seu partido, e a de Merkel em que há a proposta de mais controle na entrada de imigrantes no país, mostra como certos enunciados são ditos por indivíduos, mas acabam funcionando como enunciações prototípicas de "uma classe de locutores construída" (MAINGUENEAU, 2014, p. 52). O que se pode observar, também, é a influência do bloco europeu sobre suas nações participantes em termos econômicos e sociais. As resoluções impostas pela União Europeia têm peso tão importante quanto a própria legislação alemã e tanto Merkel como Petry reconhecem que este fato faz com que deliberações devam ser tomadas sem ter seu próprio povo como centro da tomada de decisão. Há aqueles que são a favor de uma maior integração com o continente e aqueles que questionam o quão integradas devem ser as nações. E, mais uma vez, as fronteiras mostram-se como o ponto principal desta temática, sendo os refugiados coadjuvantes deste debate. Entendendo-se este percurso, é possível nas enunciações individuais - o nível intradiscursivo - analisar o cerne da questão aqui proposta. 


\section{e. Intradiscurso}

Como se pode observar, os fragmentos selecionados se confrontam na aceitabilidade, ou não, de imigrantes cruzando as fronteiras alemãs. Tais ações seriam mais do que permitir imigrantes no país, portanto percebe-se que há um "corpus construído de sequências discursivas produzidas a partir de posições ideológicas homogêneas/heterogêneas" (COURTINE, 2009, p. 57). Petry argumenta que:

- Eu não acho que é uma questão de se sentir ameaçado, mas nós... Eu acho que no nosso país e também na Europa, cabe a nós ter de decidir qual tipo de migração queremos aceitar em nossos países. (PETRY, 2016; grifos nossos);

- A divisão já está lá, [se] nós temos que falar sobre as crianças na escola não serem capazes de fazer suas aulas de natação juntas. Se agora temos que falar sobre tempos de banho separados em piscinas públicas, não somos nós criando uma divisão, a divisão já está lá porque há diferentes origens culturais. E ser um "caldeirão-cultural" está bem. E a Alemanha tem sido esse "caldeirão-cultural" por um tempo muito longo, mas é questão de tempo e números, não é? E se eu quiser mudar para um novo país, se eu sou um imigrante, então eu acho que é bastante óbvio que tenho de assimilar a um certo grau para o novo país, se eu quiser ser uma parte dele. Isso sempre foi assim. (PETRY, 2016; grifos nossos);

- Mas decidir sobre quem está migrando e quem não está, quem é que vai fazer parte de um novo país é, no final, a questão das fronteiras, mesmo você as vendo ou não. Quando eu vou para a França, não vejo a fronteira, mas eu sei que ela está lá e a aceito, seja em termos de limites de excesso de velocidade, ou seja em termos de leis e legislação. (PETRY, 2016; grifos nossos)

\section{Enquanto Merkel sustenta:}

- Estamos trabalhando nacional e internacionalmente para melhorar a proteção das fronteiras europeias, para transformar a migração ilegal em imigração legal e combater as causas da fuga e, assim, visivelmente reduzir, o número de refugiados de forma sustentável e permanente (MERKEL, 2016; grifos nossos);

- É importante para nós para não seguir aqueles que, com frieza ou o ódio em seus corações, procuram excluir os outros, enquanto reivindicam a identidade alemã apenas para si mesmos. (MERKEL, 2016; grifos nossos)

Para as duas representantes dos partidos, a questão identitária está muito associada às próprias fronteiras. Os dois trechos selecionados de Merkel, acima, se contrapõem aos trechos de fala de Petry que os antecedem; enquanto para a atual Chanceler revisar leis e garantir a entrada e permanência de imigrantes é algo a ser debatido legislativamente, para a representante do AFD a ideia é utilizar-se destes mecanismos legais a fim de preservar a "verdadeira" identidade alemã.

Para Petry, é um fato que a Alemanha é lar para pessoas das mais diferentes culturas e que as divisões entre cidadãos alemães e habitantes de outras nacionalidades já estão claras para todos. Essa divisão seria feita naturalmente e caberia, portanto, ao povo alemão decidir como ela deveria ser realizada, ou permitida. Como dito por Petry, e destacado anteriormente na Seção 3.2, seria preciso rever as leis de asilo político e auxílio 
a refugiados. Merkel, por sua vez, já aponta que a migração ilegal pode ser vista como migração legal se determinados ajustes forem realizados. Esta ação implicaria em um fluxo maior de migrantes e incentivaria o aumento da diversidade cultural dentro da Alemanha. O embate é simplificado na questão das fronteiras, mais uma vez, exatamente pelo fato de ser por elas que os migrantes chegam à Alemanha. Decidir o tipo de migração que é aceitável - nas palavras de Petry - é escolher quem cada habitante gostaria de ter como vizinho, ou aqueles que não poderiam ser seus vizinhos em hipótese alguma.

O discurso de forte controle sobre as fronteiras da representante do AFD é rebatido por Merkel ao dizer que a identidade alemã não deve ser reivindicada apenas para alguns, sendo aberta a todos aqueles que vierem ao país e se adequarem às regulamentações ali vigentes. De certa maneira, ambos os lados pregam certo controle sobre os migrantes: Merkel diz que eles deverão seguir as regulamentações alemãs; Petry diz que as regulamentações podem ser responsáveis por quem pode, ou não, cruzar as fronteiras. Os migrantes ficam à mercê desta interpretação da lei e inconscientemente, na visão do AFD, ganham a possibilidade de uma nova cidadania ao cruzarem a fronteira, não apenas um abrigo temporário. Controlar as fronteiras é controlar quem pode, ou não, ser cidadão alemão. Pensando no que não é dito, os argumentos pendem para a questão identitária e não trazem menção a questões econômicas ou de infraestrutura.

Considerando Petry e Merkel como os sujeitos cujas enunciações sofrem influências de diretrizes sociopolíticas já antes estabelecidas, é preciso observar as implicações de suas falas em um cenário político-econômico bastante sensível. Posto que ambas as locutoras atuem como representantes de duas diferentes direções para o país, haja vista as eleições que ocorrerão em 2017, aquilo que é dito por elas permite aos cidadãos optar por dois caminhos: maior ou menor integralização com outras nações da União Europeia. Outros países já sinalizaram forte crescimento de partidos políticos indo na direção oposta da integralização entre fronteiras, como a saída do Reino Unido da União Europeia ${ }^{11}$, a forte presença do partido de Marine Le Pen na França ${ }^{12}$ e, do outro lado do oceano, a nomeação do candidato republicano Donald Trump à corrida presidencial nos Estados Unidos ${ }^{13}$. Todos apresentando uma posição muito similar ao tratamento das fronteiras de seus países: priorizar seu fechamento ao invés de sua abertura.

Em um cenário em que as leis alemãs sejam reformuladas de forma a modificar a política relacionada às fronteiras (como é fortemente defendida pelo AFD), o que se poderia antever é uma União Europeia enfraquecida, uma vez que o eixo AlemanhaFrança seria a força política e econômica que poderia dar sustentação ao bloco econômico $^{14}$, principalmente após a provável saída do Reino Unido. A reformulação das políticas acerca das fronteiras seria reformulada por todas as nações pertencentes à União Europeia em uma reação em cadeia, podendo fazer com que seu princípio de integralização entre nações perca força e até mesmo desapareça. Com menor integralização, a intolerância e xenofobia vistas em casos isolados de cidadãos europeus também podem ter aumento significativo. 


\section{Considerações finais}

Os últimos trechos apresentados ajudam a sumarizar os dois lados da questão migratória na Europa. A posição do AFD de que o controle das fronteiras alemãs deve ser mais rígido pode ser vista na fala de Petry: "cabe a nós ter de decidir qual tipo de migração queremos aceitar em nossos países". Esta proposta contrasta com o que é defendido por Merkel ao dizer que é preciso "melhorar a proteção das fronteiras europeias, para transformar a migração ilegal em migração legal", visto que para esta é possível minimizar os problemas relacionados à migração ilegal tornando-a legalizada. Tal posição também pode ser observada seguindo as diretrizes de seu partido, o CDU, em acordo com as últimas resoluções propostas pela União Europeia. Petry ainda ressalta que "decidir sobre quem está migrando e quem não está, quem é que vai fazer parte de um novo país é, no final, a questão das fronteiras", aproximando o conceito de "fronteiras" ao de "identidade". Cidadãos de diferentes culturas não estariam se adaptando ao padrão cultural alemão, na opinião de Petry, ao dizer que "a divisão já está lá porque há diferentes origens culturais", tencionando que não seria possível a imigrantes integrarem-se à identidade alemã. Merkel critica esta posição ao dizer que não se pode permitir que outros "reivindiquem a identidade alemã apenas para si mesmos".

Algumas considerações podem ser traçadas com base nos trechos aqui apresentados. O que se observa é um embate no nível legislativo da República Federal da Alemanha, uma disputa interpretativa do Estado de Direito que poderia não apenas autorizar refugiados dentro das fronteiras desta nação, mas sim redefinir o curso de certas políticas sociais que tornariam o país mais aberto ou fechado dentro de uma Europa cujas fronteiras encontram-se muito borradas - como pode ser observado não apenas nos dois discursos aqui analisados, mas também nos discursos de Merkel a membros da União Europeia e outras autoridades internacionais. Tal fato remete, também, a críticas de ambos os lados deste conflito em relação a determinadas políticas provindas da União Europeia - principalmente quando se leva em conta que o contexto histórico para tais questionamentos advém de um momento "pós-crise do Euro" - como os pronunciamentos de Merkel criticando a falta de clareza de certos dispositivos da Convenção de Dublin, ou Petry questionando se asilo político e imigração para refugiados deveriam ser tratados como uma mesma matéria.

Outro exemplo seria a maneira pela qual o combate à imigração ilegal é proposto por ambas as partes. É interessante observar que a legislação alemã, sempre muito mencionada como a garantia de uma sociedade igualitária e justa, é o pano de fundo para o manifesto de ambos partidos políticos e a salvaguarda nacional para garantir que a ordem e o progresso social e econômico serão garantidos, valendo-se disso as duas representantes partidárias para defender seus pontos de vista.

A vinda de um processo eleitoral em 2017 torna a questão humanitária em um embate político subsidiado pela própria legislação alemã. É neste palco que os sujeitos do discurso, Petry e Merkel, citam legislações, mas sempre de maneira a defender as diretrizes políticas de seus partidos. A abertura das fronteiras atribuída a Merkel transformou-se em um artifício tanto de vantagem como desvantagem para a corrida eleitoral que está por vir. Tal fato a levou a repensar as políticas de imigração, pressionada tanto pela União Europeia como por seus pares dentro do CDU. Este cenário favoreceu o crescimento do AFD de Petry. Por conta da natureza política das nações europeias, as 
próprias resoluções competentes ao continente Europeu acabam sendo colocadas em pauta, dando margem a questões relacionadas à soberania e identidade do país.

Em sendo um tópico longe de ser concluído, e cujas consequências ecoarão por um longo período, muito pode ser pesquisado sobre este assunto - como o cenário econômico está reagindo junto a parceiros comerciais da Alemanha, por exemplo, ou como a imigração em grande escala tem influenciado as diretrizes de partidos políticos de nações vizinhas. De forma a concluir a pequena fração deste tópico apresentada neste artigo, vale ressaltar que há uma voz que ecoa pelos manifestos dos partidos, passando por seus líderes e chegando aos eleitores: as regulações alemãs são o campo discursivo que permite ao locutor escolher a quais vozes dar vida e a quais silenciar. Qualquer semelhança com a travessia dos refugiados não é mera coincidência.

\section{Notas}

[1] UOL. Um olhar sobre a pior crise de migração desde a Segunda Guerra Mundial. UOL Notícias Internacional, São Paulo. 06 set. 2015. Disponível em <http://noticias.uol.com.br/internacional/ultimasnoticias/2015/09/06/um-olhar-sobre-a-pior-crise-de-migracao-desde-a-segunda-guerra-mundial.htm>; acesso em abr. 2016.

[2] THE ECONOMIST. The country formerly known as Syria: As sectarian divisions deepen, the war is changing the country beyond recognition. Syria's civil war, província de Beirute e Idleb, 23 fev. 2013. Disponível em <http://www.economist.com/news/briefing/21572198-sectarian-divisions-deepen-warchanging-country-beyond-recognition-country>; acesso em abr. 2016.

[3] BBC. Refugiados na Europa: a crise em mapas e gráficos. BBC Brasil, 06 set. 2015. Disponível em $<$ http://www.bbc.com/portuguese/noticias/2015/09/150904 graficos imigracao_europa_rm>; acesso em abr. 2016.

[4] G1. ONU destaca 'obrigação' de receber os refugiados. G1 Mundo, São Paulo, 14 set. 2015. Disponível em: 〈http://g1.globo.com/mundo/noticia/2015/09/onu-pede-que-europa-amplie-canais-migratorios.html〉; acesso em abr. 2016.

[5] GIBBS, N. The Choice. TIME, 2016. Disponível em < http://time.com/time-person-of-the-year-2015angela-merkel-choice/>; acesso em abr. 2016.

MORAIS, A. B. Obama elogia Merkel na crise dos refugiados. DN, DN Mundo, Alemanha, 25 abr. 2016. Disponível em <http://www.dn.pt/mundo/interior/obama-elogia-merkel-na-crise-dos-refugiados5142022.html>; acesso em abr. 2016.

[6] PRAGMATISMO POLITICO. Moradores de cidade alemã comemoram incêndio em centro de refugiados. Pragmatismo Redação, Xenofobia, 22 fev. 2016. Disponível em <http://www.pragmatismopolitico.com.br/2016/02/moradores-de-cidade-alema-comemoram-incendioem-centro-de-refugiados.html >; acesso em abr. 2016.

G1. Fazendeiro grego passa trator por tendas de refugiados em sua terra. G1 Mundo, 01 abr. 2016. Disponível em < http://g1.globo.com/mundo/noticia/2016/04/fazendeiro-grego-passa-trator-por-tendas-derefugiados-em-sua-terra.html>; acesso em abr. 2016.

[7] "Angela Merkel - 2016 - New Year's Speech (English Subtitles)". Vídeo do YouTube, 6:31. Postado por "compazine", Dezembro 31, 2015. Disponível em <https://www.youtube.com/watch?v=lzESJ5HoVyM >; acesso em abr. 2016.

[8] DW. Transcript: Tim Sebastian interviews Frauke Petry. DW, Alemanha, 30 mar. 2016. Disponível em <http://www.dw.com/en/transcript-tim-sebastian-interviews-frauke-petry/a-19152089>; acesso em abr. 2016.

MALM, S. German politician says migrants should be shot at border if they're trying to enter country illegally. Mail Online, 01 fev. 2016. Disponível em <http://www.dailymail.co.uk/news/article3426138/German-politician-says-migrants-shot-border-trying-enter-country-illegally.html>; acesso em abr. 2016.

[9] "Merkel vows to reduce refugee influx but rejects cap". Vídeo do YouTube, 1:22. Postado por "AFP newsagency", Dezembro $14, \quad 2015.20$ Disponível em <https://www.youtube.com/watch?v=xD0Vdk0jZ3A\&feature=player_embedded >; acesso em abr, 2016. 
[10] G1. Começa julgamento do fundador do movimento anti-Islã alemão Pegida. G1 Mundo, 19 abr. 2016. Disponível em <http://g1.globo.com/mundo/noticia/2016/04/comeca-julgamento-do-fundador-domovimento-anti-isla-alemao-pegida.html >; acesso em abr. 2016.

[11] WHEELER, B; HUNT, A. Brexit: all you need to know about the UK leaving the EU. BBC News, 21 jul. 2016. Disponível em <http://www.bbc.com/news/uk-politics-32810887>; acesso em jun. 2016.

[12] PEROSA, T. No clima pós-atentados de Paris, extrema direita tem vitória importante na França. Época Tempo, 07 dez. 2015. Disponível em <http://epoca.globo.com/tempo/noticia/2015/12/no-clima-posatentados-de-paris-extrema-direita-tem-vitoria-importante-na-franca.html >; acesso em jun. 2016.

CAÑAS, G. Le Pen faz da extrema direita o principal partido da França. El País, Paris, 07 dez. 2015. Disponível em <http://brasil.elpais.com/brasil/2015/12/06/internacional/1449433559_186847.html >; acesso em jun. 2016.

[13] DW. Trump alcança votos necessários para nomeação. DW, Estados Unidos, 26 mai. 2016. Disponível em <http://www.dw.com/pt/trump-alcança-votos-necessários-para-nomeação/a-19285327>; acesso em jun. 2016.

[14] CAÑAS, G. Merkel e Hollande alertam em Verdun, na França, contra os nacionalismos. El País, Paris, 30 de maio 2016.20 Disponível <http://brasil.elpais.com/brasil/2016/05/29/internacional/1464504470_709785.html >; acesso em jun. 2016.

GOUVEIA, J. F. Eixo franco-alemão cria roteiro para uma Europa forte. DN Mundo, 27 jun. 2016. Disponível em <http://www.dn.pt/mundo/interior/eixo-franco-alemao-cria-roteiro-para-uma-europa-forte5250601.html>; acesso em jun. 2016.

\section{Referências bibliográficas}

ACHARD, P. et al. Papel da memória. Trad. Bras. Pontes Editores: Campinas, 1999.

ALTERNATIVE FUR DEUTSCHLAND (AFD). Courage to stand up for Germany: for European diversity. National Party Convention, 22 mar. 2014. Disponível em <http://www.alternativefuer.de/wp-content/uploads/sites/7/2014/04/AfD-Manifesto-forEurope-summary.pdf >; acesso em abr. 2016a.

Political guidelines of the alternative für Deutschland (AfD). National Party Convention, 23 mar. 2014. Disponível em <http://www.alternativefuer.de/wpcontent/uploads/sites/7/2014/06/Political-Guiding-Principles-AfD.pdf $>$; acesso em abr. $2016 b$.

ALTHUSSER, L. Aparelhos ideológicos de Estado: nota sobre os Aparelhos Ideológicos de Estado (AIE). Trad. Bras. 2a . ed. Rio de Janeiro: Graal, 1985.

COURTINE, J. Análise do discurso político: discurso comunista endereçado aos cristãos. São Carlos: EdUFSCar, 2009.

CHRISTIAN DEMOCRATIC UNION OF GERMANY (CDU). Freedom and security principles for Germany. Berlim, Konrad-Adenauer-Stiftung, 2008.

MAINGUENEAU, D. Frases sem texto. Trad. Bras. São Paulo: Parábola, 2014.

Gênese dos Discursos. Trad. Bras. São Paulo: Parábola, 2008a.

Unidades tópicas e não-tópicas. Em: Cenas da enunciação. (Org. de Sírio Possenti e Maria Cecília Pérez de Souza-e-Silva). São Paulo: Parábola, 2008b. pp. 11-26. 
MAINGUENEAU, D. Discurso e análise do discurso. Trad. Bras. São Paulo: Parábola, 2015.

POSSENTI, S. Observações sobre interdiscurso. Em: Questões para analistas do discurso. São Paulo: Parábola Editorial, 2009.

Artigo recebido em: junho de 2016.

Aprovado e revisado em: julho de 2016.

Publicado em: agosto de 2016

\section{Para citar este texto:}

CARREÃO, Victor. Crise migratória na Alemanha: discursos que abrem e fecham fronteiras. Entremeios [Revista de Estudos do Discurso], Seção Temática [Os discursos sobre segurança em meio a políticas e processos de significação], Programa de Pósgraduação em Ciências da Linguagem (PPGCL), Universidade do Vale do Sapucaí, Pouso Alegre (MG), vol. 13, p. 197-212, jul. - dez. 2016.

DOI: http://dx.doi.org/10.20337/ISSN2179-3514revistaENTREMEIOSvol13pagina197a212 